\title{
Exploring the Transitional Era in Saudi Arabia Journalism Discourse and the Path towards the Right to Freedom of Expression
}

\author{
Hassan Alnajrani ${ }^{1}$, Ayman Bajnaid ${ }^{2}$, Tariq Elyas ${ }^{3} \&$ Ra'ed Masa'deh $^{4}$ \\ ${ }^{1}$ Media Department, The Islamic University, Madinah, Saudi Arabia \\ ${ }^{2}$ Faculty of Media and Communication, Communication Department, King Abdulaziz University, Jeddah, Saudi \\ Arabia \\ ${ }^{3}$ European Languages Department, Faculty of Arts \& Humanities, King Abdulaziz University, Jeddah, Saudi \\ Arabia \\ ${ }^{4}$ Management Information Systems Department, School of Business, The University of Jordan, Jordan
}

Correspondence: Hassan Alnajrani, The Islamic University, Madinah, Saudi Arabia. E-mail: hnajrani@taibahu.edu.sa

Received: May 15, 2018

Accepted: August 14, 2018

Online Published: September 7, 2018

doi:10.5539/mas.v12n10p1

URL: https://doi.org/10.5539/mas.v12n10p1

\begin{abstract}
This study investigates the role of non-state religious and cultural factors in determining a journalist's freedom of expression in Saudi Arabia. Content analysis and quantitative research are used to determine the factors that impact freedom of expression. 'Social responsibility theory' is incorporated into the analysis in order to establish the connection between journalists and the community, specifically with respect to their interaction with non-state factors. The data for the study is collected and interpreted in two steps: first, news about events in Medina newspaper is examined; second, interviews with Saudi journalists are conducted and analyzed by implementing a semi-structure approach. The results confirm the relationship between non-state factors (such as culture and religion) and freedom of expression for Saudi journalists. Also, the religious background of Saudi journalists appears to affect their right to practice freedom of expression; for instance, some journalists with specific religious views avoid writing about rape and drugs crimes. In addition, journalists change their tribal and family names to escape judgment and work freely. Finally, some concluding remarks are provided about the responsibility of Saudi journalists to protect the image of Saudi Arabian society.
\end{abstract}

Keywords: discourse, journalism, Saudi journalists, Saudi society, freedom of expression

\section{Introduction}

Saudi Arabia has been defined as a conservative country that is founded upon an alliance between Islmaic religion and secular authority on its normal of life (Elyas \& Picard, 2012; Mahboob \& Elyas, 2014; Darawsheh, et al., 2016; Elyas \& Picard, 2018). However, in recent years, the country has witnessed dramatic changes toward becoming more moderate in its policies, specifically with respect to individual freedoms. Journalism is one of a number of occupations that have increased and become more vigorously practised. While it is clear that freedom of expression has not yet been fully secured, it is still in its emergent stages and capable of further expansion. Therefore, Newspapers, Television, and Radio are as important as ever in shaping public opinion and government trends (Alghamdy, 2011; Masa'deh, et al., 2013). However, social media such as Twitter and Facebook have provided new platforms for people to say what they think (Maqableh, et al., 2015; Allam, et al., 2017; Aljasir, et al., 2017a, 2017b, 2017c; Obeidat, et al., 2017). Without a doubt, freedom of speech on social media has evoked a reaction in the landscape of journalism, as journalists themselves have started to use these means of communication to cross red lines in comparison with traditional media. Indeed, Saudi Arabia is in a transitional stage. Therefore, the common idea that the state controls media content may no longer be applicable. There are other factors that have been neglected in the previous literature that may restrict the freedom of Saudi journalists more than the state itself. Also, the differences in the levels of freedom of expression possible for different cultural and religious groups in Saudi society could have an impact on the way that this issue is addressed. Thus, particular customs may direct and restrict journalists' freedom of expression, and an exploration of this phenomenon may reveal how culture shapes the concept of freedom from within a particular society (Shannak, et al., 2012; Bajnaid \& Al-Saggaf, 2017; 
Bajnaid \& Elyas, 2017). Further, the current research aims to investigate the role of non-state cultural factors in determining a journalist's freedom of expression in Saudi Arabia. Specifically, the paper will examine the extent to which Saudi journalism traditions and customs affect Saudi journalists' freedom of expression; investigate the extent to which religious affiliation affects Saudi journalists' freedom of expression; determine Saudi journalists' understanding of social responsibility and how they work to achieve it; and use social responsibility theory to understand how social and religious factors can impact a Saudi Arabian journalist's job.

In addition, in Western studies, there is a lack of information in the literature about freedom of expression in Saudi Arabia. This paper will also shed some light on the factors that shape freedom of expression in the journalism field in Saudi Arabia, with a focus on religious practices and cultural tradition, in an attempt to fill this gap in the literature. More specifically, the extent to which religious affiliation affects Saudi journalists' freedom of expression is investigated. Saudi Arabian journalists' understanding of their own social responsibility in relation to how social and religious factors impact their jobs is also explored.

\subsection{Journalism in Saudi Arabia}

Newspapers in Saudi Arabia were established early in the twentieth century around the time when the country was unified under King Abdulaziz. It has been noted that the country's kings were interested in establishing newspapers and magazines in the early 1900s. Thus, at that time, there was freedom of speech sufficient for the founding of a newspaper or a magazine. In 1932, the government officially allowed individuals to launch newspapers. One of these papers was SawtAlhejaz, the Voice of Hejaz, which was founded in Makkah, and another was the Almanhal magazine, which was created by Abdulqadous Alansari. In 1954, some other cities around Saudi Arabia established newspapers, such as Althahran News and Alnadwah in Makkah (King Saud History website). However, in 1958, the Saudi government reorganised the press landscape and combined a number of newspapers, with the result that individuals encountered difficulties in establishing their own newspapers; this period marked the end of the individual newspaper age. In 1962, the Saudi Kingdom declared that newspapers should be non-government organisations and their administration must contain more than 15 people. This Article included 34 conditions that covered matters such as the election of members and the chief editor. Moreover, in the 1970s, the Saudi government started to launch English newspapers, such as the Saudi Gazette and Riyadh Daily (King Saud History).

The press for Saudis was the only source of public information on what was taking place in the kingdom. For many decades, newspapers published reports, whether official news or opinions of the public. In addition, before the advent of widespread broadcasting venues, people could not count on any other source for news other than newspapers. As a result, these newspapers were able to exert power over a massive audience and effectively shaped their opinions, including their views about what qualified as a credible source. For instance, although readers may now receive news from different broadcasting venues such as electronic resources or overseas publishers, they are reluctant to believe these reports until they see and touch them in print, since other sources may be considered to be fake (Alghamdy, 2011; Berger, 2013; Al-Dmour, et al., 2015).

By law, the Saudi press now works under the control of the government, and any transgressions of editors through criticism of religion, members of the Royal Family, or government policies are forbidden. Therefore, journalists are prevented from discussing many important problems (Alghasha'ami, 2006). Among the other ways in which the press is controlled in Saudi Arabia is that the appointment of Editors in Chief is decided by the Ministry of Information with agreement from the Ministry of the Interior, which ensures that the state will be able to monitor the newspapers. Moreover, a number of steps must be executed before a prospective publisher can get permission from the government to launch a new newspaper. The launch must be established by Royal Decree. Newspapers must meet several conditions, such as having no fewer than 40 Saudi shareholders, all of whom must have a record clear of any security offences. As a result of such restrictions, the government now monitors the press directly through regulation, censorship, and direct supervision (Alghamdy, 2011).

There are currently nine companies publishing newspapers in Saudi Arabia (AlAwad, 2010):

- Makkah Establishment for Printing and Information, founded in 1964 and based in Makkah, publishes Al-Nadwa, which changed its name to Makkah in 2013;

- Al Medina Press Establishment, founded in 1964 in Jeddah, publishes a daily newspaper, Al-Medina;

- Al-Yamama Press Establishment, founded in Riyadh in 1964, publishes the daily Alriyadh;

- Okaz Organisation for Press and Publication, established in Jeddah in 1965, publishes the Okaz daily;

- Al Jazirah Press, Printing and Publication Establishment, founded in 1964 in Riyadh, publishes the daily Al Jazirah; 
- Al-Bilad Press and Publication Establishment, established in Jeddah in 1964, publishes the daily newspaper AlBilad and the weekly magazine Aqra'a;

- Dar Al-Yawm Press and Publication Establishment, founded in Dammam in 1965, publishes the Al-Yawm daily;

- Alsharqyah Establishment for Press, Printing and Information, founded in 2011 in Al Dammam, publishes the newest daily newspaper, it is Alsharq.

- Assir Press and Publication Establishment, founded in 2000 in Abha, publishes the newest daily newspaper, Alwatan.

The Saudi Arabian government strictly controls the content of these newspapers through the Ministry of Culture and Information. In addition, the government takes news published in newspapers more seriously than online journalism. Officials tend to interact with newspaper journalists who broadcast or release their statements through their newspapers, thus limiting the role of the online or unauthorized journalist in participating in public affairs. Despite these limitations, blogs began to appear in Saudi Arabia in 2003 and had become common by 2006. Some bloggers prefer to be anonymous. Fouad Alfarhan was among those bloggers who appeared under his real name, and after writing some posts in opposition to the government, he was arrested (Levy, 2009). Social media applications have now expanded the possibilities for freedom of expression, and journalism has benefited from this expansion. Twitter has been especially important in this respect (Alejandro, 2010; Almaghlooth, 2013). Twitter's CEO, Dick Costolo, has said that Twitter has more than 140 million active users. In particular, Twitter's growth is coming from the Middle East. Costolo mentioned that in June of 2012, Saudi Arabia alone reported an increase in Twitter use of 3,000\% (Guynn, 2012). In addition, Anne Gaviola, a journalist for CBC, has reported that Saudi Arabia has the highest Twitter breakthrough proportion in the world at about $40 \%$. These percentages ensure that Twitter is more important to Saudis than any other social media platform (Ahlam \& Elyas, 2016; Allam, et al., 2017).

Compared with some of the larger countries in the world, Saudi Arabia has a relatively small number of newspapers, which reflects the limitations on freedom of expression in the country. In January of 2011, the Ministry of Culture and Information established a licensing requirement for all new and existing online newspapers. The Saudi government told managers of e-newspapers that if they did not get a license within six months, their websites would be shut down (Jawad, 2013; AlOmran, 2012). Almaghlooth (2013) argues that religious monitoring plays a key role in the production of news in Saudi Arabia, and its influence extends across the landscape of media. Religious and social influence on the media landscape in Saudi Arabia has had a strong impact on every aspect of life inside the country. For example, there are limitations on the appearances of Saudi women on national television (Marghalani, Palmgreen, and Boyd, 1998). Moreover, as a result of social and religious considerations, Saudi women work in isolated sections inside newspapers. Because religious leaders have encouraged this practice of gender separation, it is difficult for men and women to work together. All of these various factors combined have adversely affected the production and distribution of content through the Saudi Arabian media.

\section{Research Methodology}

The current research aims to investigate the role that non-state factors have in determining a journalist's freedom of expression in Saudi Arabia. As a result, it is important to examine the relevant data that will provide a deeper understanding of this topic. The qualitative approach to data analysis is a complex, dynamic, and challenged field, consisting of a wide variety of methodologies. Thus, the qualitative method is not a single structure, but an umbrella term (Punch, 1998; Al Azmi, et al., 2012). Amaratunga, Marjan \& Newton (2002); and Tarhini, et al. (2015) suggest that the qualitative method can be used to focus on words and observations in order to express the reality of individuals in normal situations.

\subsection{The Research Design}

This study was conducted in two stages. First, content analysis was used to determine how newspapers deal with good and bad news. Second, questions were formulated on the basis of the content analysis and used in interviews with journalists.

\subsubsection{Phase One: Content Analysis}

The content analysis involved actual published data by Saudi newspapers. First, reports from Saudi newspapers were analysed in order to determine if they were related to the goal of this research. Therefore, three positive reports and three negative reports (six reports in total) were selected in order to clarify how Saudi journalists deal with a specific topic, and to determine if they were exhibiting signs of freedom of expression. Town newspapers were selected because they have the same stories and are generally socially accepted. The journalists all worked in Medina. The newspapers were Al-Medina and Okaz. 
Various questions were asked in the analytic process: (1) Is this good news or bad news? (2) If bad news is reported, does the article contain information about actions such as rape or drug use? (3) Did the journalist use his or her family name in the report? These initial questions facilitated further reflection on the influence of tradition and religion on the content of the reports.

\subsubsection{Phase Two: Interviews}

Bhattacherjee (2012) asserts that the success of a qualitative approach in the analysis of data, such as an assessment of information obtained from interview transcripts, depends on the researcher's analytical skills and his or her understanding of the social context from which the information is taken. The strength of this approach is that it allows the researcher to explore factors that play a role in determining the expression of freedom among Saudi journalists. In employing a qualitative approach in the interviews, Bauman \& Greenberg (1992) describes how important it is for the interviewer to be a good listener and attentive to details in order to be able to draw out the relevant information from the responses of the interviewees. Interviews were conducted on a one-on-one basis in order to ensure that the data from the interviews provided deeper insight into the phenomenon under investigation. Certain observations were made, and the results were recorded. Using thematic analysis throughout the process by recording interviews and analysing them systematically, the clearest results about the impact of religious and cultural factors affecting freedom of expression among journalists in Saudi Arabia were able to be determined. A semi-structured approach was beneficial because questions could be organised that they were shared with the interviewee before the interview ahead of time in order to allow the interviewer to be prepared for the interview. A semi-structured approach gives participants the freedom to express their views in their own words. Also, it can provide reliable and comparable qualitative data.

The sample consisted of ten journalists, five belonging to tribes, and five belonging to families. There were five males, and five females. These journalists were chosen from different newspapers from Medina. They were aged between 25 and 35 years, and they each worked for different daily newspapers. Three of them were editors and seven were correspondents. Participants were selected on the basis that they were exposed to changes that have occurred regarding freedom of expression over the last fifteen years in Saudi journalism. They all had between five and fifteen years of experience working with the following journals: the Riyadh newspaper, the Al-Medina newspaper, the Okaz newspaper, the Makkah newspaper, and the Al-watan newspaper, all of them being from Medina. Interviews were conducted and recorded using Skype.

\subsubsection{Interview Questions}

Questions about freedom of expression and how journalists deal with cultural and religious factors were formulated. Also, more specific questions were asked about freedom of speech. Other questions were formulated which allowed the researcher to determine the kind of interaction the journalists had with Saudi society

The first set of questions was focused on personal issues, and they were formulated as follows:

1. Do you display your tribe/family name in media reports? Why?

2. Why do you think journalists change their family name in newspapers?

3. Has anyone from your group of friends, family, or tribe condemned you for writing any report? If so, has this affected your future reports?

The next set of questions delved further into religious issues in Saudi Arabia, and how religion may affect the journalist's occupation:

1. Do you believe that Medina's position as a holy Islamic city affects your reporting as a journalist? If so, could you explain how/why?

2. In your work, have you been condemned by religious people or from a religious point of view?

3. To what extent do religious factors shape your journalistic activity?

Next, questions were asked about the relationship between journalists and editors, who sometimes have an impact on the expression of freedom of Saudi journalists:

1. What are the circumstances that might lead to your editor rejecting a report that you have submitted?

2. What are the topics that you believe you should cover but that are considered to be out of bounds?

3. Is there some news that should not be written about in Medina? Why?

Finally, there were some questions that addressed the relationship between the government and Saudi journalists:

1. Have you ever been investigated by the Medina government? If yes, why? And how was the issue resolved? 
2. Have you encountered any issue with your family/tribes about writing bad news? If so, could you explain further?

\section{Results and Discussion of the Interviews}

\subsection{Content Analysis}

Content analysis of news reported in Medina revealed that Medina news could be affected by social and religious factors which were especially related to the religious status of Medina. Historically, the city is the location where the prophet Mohammed was received and it is also an assembly point for Muslims. It is generally considered to be the second holy city for Muslims. Saudi people respect Medina and try to reflect this attitude in their occupations and behaviours. Furthermore, some Saudi journalists avoid reporting bad news because it could impact Medina's reputation. Even though journalists and newspapers may be aware of bad news relevant to Medina, such as drug use and rape, it is clear that such bad news could be detrimental to the reputation of Medina among Muslims and other people around the world. Taking this into consideration, journalists may be inclined to report only good news about Medina and to ignore the bad news. The Medina reader's point of view regarding the journalist's job could be negative if he or she published bad news. On the other hand, it seems as though readers do not consider that journalists might cross other lines into corruption in order to avoid such reports, since readers may feel angry if there is news about rape or drugs. Some journalists even go as far as avoiding use of their family or tribal names when reporting bad news, which could still be detrimental to their reputation.

Despite this cultural and religious pressure, some bad news is still reported. For instance, the Al-Arabiya channel disseminated bad news about a girl who was kidnapped, raped, and killed. However, there were no journalists that were willing to report it. Some journalists have bad news that is considered to be less damaging to Medina's reputation than rape and drug-related crime. For example, Ayman Alssaydalani, who works for the Okaz newspaper, reported the case of stolen of equipment from a dental clinic. Still, he changed his tribal name in his report in order to feel secure in his journalistic position. Thus, minor offenses may be accepted by readers of Medina, but journalists might still feel insecure in reporting them. Thus, the content analysis of news reports in Medina led to the formulation of the questions used in the interview in order to confirm that religion and culture have a significant impact on the freedom of expression of journalists in Medina.

\subsection{Interview Analysis}

The interviews examined how social and religious factors can impact the freedom of expression of Saudi journalists, and also how these factors have been shaping the journalism field itself. Naturally, elements of the journalism landscape are impacted as the journalists carry out their normal work. Without any doubt, there are others factors such as politics and advertising that also affect freedom of expression in this context. Although they certainly cannot be ignored, they do not hold the same weight as social and religious factors. Thus, four themes have emerged from the interviews, and journalists have agreed on the importance of these themes in restricting their freedom of expression:

\subsubsection{Religious Concerns}

Religion has an important impact on the journalists I interviewed, and they relayed a lack of freedom in this respect, drawing specific attention to the power that religion has over their journalistic work. There are three specific ways in which religion exerts this influence:

\subsubsection{Fear of Power of Religious People}

During the interviews, some participants conveyed that they were afraid of the power of religious people, either the members of society who follow strict religious rules, or the Mutaween, also known as the 'religious police' or the Committee for the Protection of Virtue and Prevention of Vice. F4 reported that she had criticized a story relating to members of a religious sect, and some of them wrote about her on a website including her personal details, such as where she lives, her job, and her family. They tried to tell her to avoid writing about negative news that has religious implications. She was frightened by their way of dealing with her criticism. In addition, M4 reported that religious men attempted to directly affect his journalistic career. He said that one day the newspaper asked him to cover an event. When he arrived, the religious men ordered him to leave, because, according to Saudi law, you cannot work during prayer. Therefore, they ordered him to leave the area, but he refused and continued the interview. They told him that if he did not leave, they could arrest him. Finally, he left the area before an arrest could be made. M4 expressed that sometimes religious men do not understand and respect his job as a journalist. He maintained that although clerics exercise power over journalism, journalists should struggle against this supposed authority.

On the other hand, although some journalists have been accused of insulting religion, the majority of them defend 
themselves by claiming to have high levels of respect for religious authority. They believe that one of their important missions is to reveal reality and that their jobs as journalists are also a part of their religious work. For instance, M3 said that he published a story about a non-Saudi citizen using the back-part of a mosque to practise magic. Some religious people accused him of corrupting their image and the mosques. He refuted this accusation and told them that it was part of his responsibility for religion and society. Along the same lines, M1 argued that journalists should expose issues that could improve the condition of the community. For example, he released a report about the exploitation of poor people in collecting proceeds for a charity. As a result, the government prevented those people from collecting money via direct state involvement. Subsequently, he was criticised for his story as it could have a negative impact on good people helping poor people. M1 said that he was not concerned about this attitude, because from his religious point of view, he published the story to prohibit the money from being used for unworthy ends.

From the interviewees' statements, it appears that there are three types of power that could affect journalists' freedom of expression. First, there is the ability to ruin someone's reputation. Saudis, in general, admire anything related to their religion, and some who consider themselves as religious (not only religious police) accuse journalists of not respecting their religion. Some may threaten to expose the personal information of the journalist, or even go as far as to do so. This kind of power negatively affects the freedom of the journalist. The second type is the power that stems from the authority that the religious police hold. Whilst this kind of power does not directly affect freedom of expression, it places obstacles in front of the journalists when they work outside of the office. For instance, they can be accused of ignoring instructions or working during prayer time. The third type of power stems from religious people having influence over some organisations such as charities that work to help poor people. Some of the heads of these charities put pressure on the journalists so that they do not report negatively about them. At the same time, they cannot prevent journalists from reporting, but they find other ways to discontinue the circulation of bad news about their organisations. Thus, this indirectly stops a journalist's activities, and restricts their freedom of expression.

These factors do not have a comparable amount of influence in Western media because of the existence of democracy. It can be seen that this religious factor is influential on the expression of freedom in Saudi Arabia, and it is not a political factor.

\subsubsection{Ignoring Women's Activities}

Most of the men and women who participated in the interviews believed that the religious factor is brought to light when paying attention to women's news. Every society has its own specific cultural features, and women in Saudi culture veil their faces (Bajnaid \& Elyas, 2017). As a result, journalists have to be careful when taking pictures of events that include females. F1 said that activities involving women lack an appropriate amount of coverage because the religious culture prevents journalists from taking pictures of a woman's face or of her actions. She claims, 'I cannot take pictures of girls when I cover any events. Some people think that this is against Islamic law and others have concerns about the showing of pictures on the front or inside pages of newspapers. By the way, some religious members demand that we stop publishing pictures of women, and in some cases we follow their restrictions.' F3 admitted to addressing the issue without fear and has published articles on women's activities. Although facing additional demands, she has still continued to work at her job. M1 mentioned that while the religious members might claim that they can stop us from circulating pictures of women and their activities, 'We broadcast pictures of women after getting permission from them and their families. They allow us to publish the pictures of women, and [religious authorities] should not stop us'.

Reviewing the content of Saudi newspapers reveals that there is coverage of women's activities, and there are women's photos in them. However, it seems that this work is not as simple as it looks. Journalists in the interviews expressed their frustration, as they felt that there are some restrictions in their fieldwork. They were aware that it is a female's right to decide to publish her photo or not, and they are aware that religious people do not have the authority to prevent any materials from being published. However, religious people can attend a women's event, such as cultural event, and prevent journalists from taking pictures of women without their express consent because this is against the law.

Obviously, the fervour of people who have strong religious backgrounds could impact journalists, limiting their freedoms and maybe prohibiting them from being able to do their jobs. Most importantly, these actions could prevent journalists from doing their duty; as part of their responsibility to society, they should not intentionally avoid reporting on any aspect of the community, and women represent half of the community. In western media, feminist movements have led to increasing equality between men and women. These attitudes help to balance news that focuses on males and ignores women's activities. In contrast, Saudi journalists try to avoid women's 
activities for both cultural and religious reasons. Thus, Saudi journalists prefer to ignore writing about these subjects because there is conflict between religious and cultural matters. As a result, the religious factor is an important reason why there is limited coverage of women's activities.

\subsubsection{Pressure of Norms}

This theme refers to the two ways in which norms can put pressure on journalists. Journalists have found that social and cultural pressures shape their journalistic activities, and they have described some points that clarify the merits of intervention. These interventions could be from families, tribes, or society in general.

\subsubsection{Tribe, Family, or Society}

In some cases, a tribe, family, or society can accept the individuals who choose to work in journalism. However, they can also have a negative impact on journalists' careers. F1 reported that her family strongly supports her. However, some members of society tried to pressure her family into stopping her when she published news against the members' interests. For instance, she says that she once reported on a story about corruption in a charity. The manager of the charity went to her family and told them that the story was inaccurate. He also claimed that this story could negatively impact the reputation of the charity. Her family requested that she apologise through the newspaper, but she refused. She said the relationship between journalists, their families, and members of society are complicated. In addition, she said, 'Unless the journalist severs the relationship with society, he/she will fail, and it may have an impact on the journalist's job.' She added, 'Family and tribe cannot support a journalist forever. Any moment they could be separated, leaving the journalist to face the issues alone. Thus, a journalist should understand the relationship between family and society and he/she will do the job perfectly'. On the other hand, M5 said he displays his surname proudly. He admitted that pressures come from society because he sometimes reports bad news that uncovers negative sides of the society. For example, he once published a story about a singer. In some Islamic doctrines, singing with musical instruments is prohibited. Therefore, to some, this singer had done something wrong. Therefore, when M5 published an interview with the singer, some people criticised him directly, arguing that he should not have written about the singer because of opposition in society to singing with musical instruments. Such pressure in this case came from society, but in other cases, it can come from one's tribe or family.

Tribes, families, and societies can intervene in ways that may be detrimental to the careers of the journalists. Reporting bad news specifically encourages people to try to convince journalists to change stories. There are two kinds of reports that often lead to such interventions in journalism. First, bad news about organizations or individuals could increase pressure on the journalists. Secondly, reporting about people who work in controversial occupations such as singing can also lead to interventions. It is clear that people use families and tribes, or in other cases simply themselves, to limit Saudi journalists' freedom of expression. The difference between individualism and collectivism can help make sense of how western journalism differs from Saudi Arabian journalism. Hofstede (1980) states that individualist communities call for independence, the right of privacy, and financial security. Collectivist communities, in contrast, focus on collective identity, sharing, group solidarity, and group decisionmaking. Thus, journalists in Saudi Arabia live in a collectivist society and are therefore significantly impacted by the pressures of tribes, families, and society.

\subsubsection{Image of the Ideal Journalist}

A majority of the journalists questioned focused on an ideal journalist's image and suggested that the role of the ideal journalist should be to reflect on society. In addition, a journalist should understand the importance of their context, whether it be a small village or a massive city, a religious location or a tourist attraction. The theme of the ideal journalist was revealed in two concerns that were expressed during interviews:

\subsubsection{ProtectingSociety's Image}

During the interview, F2 stated that protecting community image is crucial. Furthermore, since she is located in Medina in the heart of the Islamic city, she is expected to avoid publishing news related to rapes, murders, and pornography. For example, she once had information about a rape but refused to send it to newspapers because she knew how Muslims respect Medina and felt, as a citizen, that this news might distort the image of the city. Moreover, she says, 'Medina has a great image because of its Prophet Mohammad's grave and the massive numbers of Muslims that come every year to visit the glorious place. On the other hand, visitors need to be comfortable with Medina's society. Thus, journalists of Medina should care about society's image'. M4 pointed out that Medina's position as a holy city affected his journalism by his abstention to publish bad news, particularly news related to sexual issues. He explains that, 'Sexual issues are rare and it is not common to covet. If something happens rarely, we cannot highlight it. It is unfair. There are other issues that do not usually occur, such as killings or porn. Only one of these rare issues cannot draw a bad image of society, but as a journalist one should still avoid 
covering it'.

There are three reasons why such reports are avoided. First, the community image will be protected by stopping the broadcasting of bad news that relates to sexual news or killings. As a result, journalists can be seen as people who care about the image of their community. They try to decrease bad news to improve the image of Medina for people who like the holy city. Second, these kinds of events are rare and not significant enough to risk Medina's reputation. Third, there is a commitment to depicting Medina as a safe city and the society as modern. This depiction both reflects and promotes the image of Medina. The ideal image of the journalist is something that cannot be discerned in western cultures to the same extent. While journalists in western countries work without restrictions and barriers, the components of the ideal journalistic image in Saudi society condition the behaviour of Saudi journalists. In addition, Saudi culture is reflected by the journalist, and society presents him/her as an ideal person who protects society.

\subsubsection{Job Security}

Some journalists fail to publish their stories. They sometimes do not meet the requirements for publication in the same way as one could refuse to provide a statement for police about a murder. Thus, to provide all of the content related to a report is a part of maintaining job security.

In one of his earliest positions as a journalist, M4 reported that his stories were sometimes rejected because he did not bring a statement from police or a spokesperson. On the other hand, some reports were simply not worthy of publication, having ridiculous stories or repeating news already published in other newspapers. Poor news quality cannot pass over editing desks in newspapers. F2 expressed that some news could not be authorized because it was too old. She confirmed that a lack of broadsheet material could prevent publication.

Through interviews with journalists, it is apparent that there are two types of journalism that do not meet the requirements. A lack of fundamental and important news support such as statements of government officials confirming that something had happened can prevent material from being published. Second, some news is either just too old, or has already been published. For instance, Hajj happens every year, so some journalists recycle news and simply change the date. They do not care enough to work hard on finding new stories. As a result, such news is often prevented from being published. Thus, news should be new, complete, and contain all of the required elements for publication.

The NUJ in the United Kingdom provides an identity card to professional journalists. It indicates that journalists are qualified and professional. However, anyone in Saudi Arabia can be a journalist whether he/she is qualified or not. Consequently, the process by which a story becomes an official news report requires official confirmation, and must conform to other standards for publication.

\section{Research Conclusions}

\subsection{Summary of Findings}

This study has focused on freedom of expression for Saudi journalists. It has revealed that there is some lack of freedom, and the reasons behind the limitations on freedom of expression have been described. More specifically, the role of social responsibility and non-state factors in determining a journalist's freedom of expression were examined. The objective was to show how cultural and religious factors impact the freedom of expression of Saudi journalists, and that the relationship between journalism and non-state factors could hinder this freedom. This objective has been met in light of social responsibility theory.

In order to determine Saudi journalists' understanding of their social responsibility and how they work toward achieving it, interviews were conducted to examine how social and religious factors can impact a Saudi journalist's job. Some of the limitations in freedom continue to persist due to pressures from others in society, the professional discipline of the journalists themselves, their editorial colleagues, or the specific policies of the newspapers that employ them.

There are some international declarations that are designed to protect freedom and assist in ensuring freedom of speech for all (Baker, 1992; Rosenblatt, 2011). For example, Article 19 of the Universal Declaration of Human Rights states that 'everyone has the right to freedom of opinion and expression; this right includes the freedom to hold opinions without interference and to seek, receive and impart information and ideas through any media and regardless of frontiers.' In addition, the International Covenant on Civil and Political Rights (ICCRP) protects freedom of speech in its Article 19:

Everyone shall have the right to freedom of expression; this right shall include freedom to seek receive and impart information and ideas of all kinds, regardless of frontiers, either orally, in writing or in print, in the form of art, or 
through any other media of his choice.

However, although these rights have been formalised in international declarations, whether or not they are secured depends on the particular context in which they are applied, or even recognized. Social responsibility theory can come into play here, in the sense that it is able to explain how societies can assure that individuals have the right to respond to community issues. Novak (1996) have debated the advantages of social responsibility as a method of assuring that people behave in accordance with what is taking place in the private or public sector. For instance, avoiding causing harm to one's community is a kind of social responsibility. Responsible individuals must help to develop the social framework where they live and care for society by maintaining it and contributing to it (Bunton, 1998; Kaliski, 2001; Christians \& Nordenstreng, 2004; Fackler \& Fortner, 2010).

While it can be said that freedom of expression is essential for the development of society, social responsibility itself is even more important. Thus, social responsibility theory can facilitate understanding of the complex relationship between media and community. That being said, social responsibility has a distinctive meaning in the media landscape. In the earliest years of the twentieth century, it was widely believed that the U.S. would embrace the norms of social responsibility. In 1947, Robert Hutchins headed the Commission on Freedom of the Press to reassure the public concerning the increasing fear of the credibility of the press. At the conclusion of their work, Hutchins's team derived two essential conclusions that shaped the application of social responsibility theory to the media: (1) the press has a responsibility to the community; and (2) the libertarian press of the U.S. had transgressed the required norms of social responsibility. The consensus was that press had to be controlled by the views of society, specifically the readers and observers, and be held accountable by the standards of professional ethics. The Commission's goal was to ensure that the media landscape would be worthy of continuing its dissemination of the news (Mills, 2009).

\subsection{Contribution}

Three themes have emerged through this study that reflects the concerns of the journalists regarding their freedom of expression: (1) religious concerns and the power of religious people; (2) the lack of publication of women's activities; and (3) the pressure of norms in social behaviour. All played a part in defining the amount of freedom of expression available in Saudi journalism.

This study has determined how cultural and religious factors shape freedom of expression among Saudi journalists. Furthermore, it tries to answer the question, 'Do Saudi journalists have the right to freedom of expression?'

First, there is no similarity between western societies and the Saudi community relating to religious influences because western governments are generally secular and democratic. Thus religion is a powerful force affecting freedom of expression in Saudi Arabia. There may be a lack of western understanding of freedom of speech in the practice of journalism of Saudi Arabia. This lack of understanding relates to effect that religion has on the expression of freedom.

Second, ignoring women's activities is common in Saudi Arabia. In western communities, feminist movements have initiated changes in support of equality between genders. However, some Saudi journalists try to avoid women's activities for cultural and religious reasons. The conflict between religion and culture plays a vital role in shaping this complicated situation. Thus, Saudi journalists avoid attending women's events.

Third, escaping of judgment is common concern in most societies. In western, communities, everybody has his/her own right to privacy. On the other hand, people in Saudi Arabia adapt to tribes or families and this relation impacts the freedom of expression that people have. Therefore, individuals take their speech under consideration to avoid criticism of society.

Fourth, there is a fundamental difference between western society and Saudi Arabia society in terms of individualism and collectivism. In western societies, the communities are individualistic. People are independent and have the right of privacy and financial security. In contrast, Saudi society is collectivist. Journalists are therefore impacted by the pressure of their tribes, family, and societies.

Fifth, journalists in western countries do have not any restriction from society. However, the components of the ideal journalistic image in Saudi society play a dynamic role in shaping the Saudi journalist's image.

Sixth, there is a similarity between some European countries such as Britain according to the interests in protecting their image. The example was used of the British army in the Falklands controlling the media in order to protect the image of Britain. In Saudi Arabia, some journalists avoid reporting bad news that could affect the market of Medina and instead opt to protect the image of Medina.

Seventh, there are non-profit organisations that work to protect journalists in western countries from others such 
as advertisers. In contrast, in Saudi Arabia, there is no active organisation to protect their interests.

Eighth, in western countries, there are organisations such as the National Union of Journalists in the United Kingdom which provides an identity card for professional journalists. It indicates that journalists are qualified and professional. However, any one in Saudi Arabia can be journalist whether they are qualified or not. Thus, newspapers could ignore some news from journalists who do not present full story. The current study opens the way for other studies to look in depth at freedom of expression inside journalism in Saudi Arabia. Also, this study paves the way for new studies in the same area that implement qualitative and quantitative approaches.

Finally, different features of the societies should be considered. In addition, the paper contributes to the knowledge by revealing non-state factors that affect freedom of speech in Saudi Arabia in order to draw attention to these differences. The study has touched on some new points that need to be revealed in order to advance the understanding of the freedom of speech in Saudi Arabia.

\subsection{Limitations and Recommendations for Future Studies}

This study had a limited amount of time and a small sample. The time limitation has definitely affected the quality of the results. More time and flexible dates may be of assistance in the discovery of other factors in order to draw a more accurate picture of Saudi journalists' freedom of expression. Thus, the results of this study cannot necessarily be generalized. The study opens the way for other studies to look in depth at freedom of expression inside journalism in Saudi Arabia. Also, this study paves the way for new studies in the same area that implement a quantitative research method.

\section{References}

Al Azmi, N., Al-Lozi, M., Zu'bi, Z., \& Dahiyat, S. (2012). Patients Attitudes toward Service Quality and its Impact on their Satisfaction in Physical Therapy in KSA Hospitals. European Journal of Social Sciences, 34(2), 300314.

Al Omran, A. (2012). Royal Rules in Saudi Arabia, Oslo Freedom Forum.

AlAwad, T. (2010). The Saudi Press and the Internet: How Saudi Journalists and Media Decision Makers at the Ministry of Culture and Information Evaluate Censorship in the Presence of the Internet. PhD Thesis, University of Sheffield.

Al-Dmour, R., Obeidat, B., \& Almajali, D. (2015). The Practice of HRIS Applications in Business Organizations in Jordan: An Empirical Study. 4th Scientific \& Research Conference on New Trends in Business, Management and Social Sciences (COES\&RJ-TK15/1).

Alghamdy, S. (2011). A Step towards Democracy? 2005 Municipal Elections in Saudi Arabia. PhD thesis, School of Journalism, Media and Cultural Studies.

Alghasha'ami, M. (2006). Thoughts and the Censor, Modern Academy for University Books.

Aljasir, S., Bajnaid, A., Elyas, T., \& Alnawasrah, M. (2017a). Facebook's Compatibility, Reasons for Disclosure, and Discussion of Social and Political Issues: The Case of University Students Using Facebook. Journal of Management and Strategy, 8(5), 1-17. https://doi.org/10.5430/jms.v8n5p1

Aljasir, S., Bajnaid, A., Elyas, T., \& Alnawasrah, M. (2017b). Themes of Facebook Status Updates and Levels of Online Disclosure: The Case of University Students. International Journal of Business Administration, 8(7), 80-97. https://doi.org/10.5430/ijba.v8n7p80

Aljasir, S., Bajnaid, A., Elyas, T., \& Alnawasrah, M. (2017c). Users' Behaviour on Facebook: A Literature Review. International Journal of Business Administration, 8(7), 111-129. https://doi.org/10.5430/ijba.v8n7p111

Allam, M., \& Elyas, T. (2016). Perceptions of Using Social Media as an ELT Tool among EFL Teachers in the Saudi Context. English Language Teaching, 9(7), 1-9. https://doi.org/10.5539/elt.v9n7p1

Allam, M., Bajnaid, A., \& Elyas, T. (2017). Using Twitter as an ELT Tool in the Saudi EFL Context. International Journal of Linguistics, 9(5), 41-63. https://doi.org/10.5296/ijl.v9i5.11813

Almaghlooth, A. (2013). The Relevance of Gatekeeping in the Process of Contemporary News Creation and Circulation in Saudi Arabia. PhD Thesis in Digital Media, University of Salford, UK.

Amaratunga, D., Marjan, D., \& Newton, S. (2002). Quantitative and Qualitative Research in the Built Environment: Application of "Mixed" Research Approach. Work Study, 51(1), 1731. https://doi.org/10.1108/00438020210415488 
Bajnaid, A., \& Al-Saggaf, Y. (2017, November). Impression Formation on Matrimonial Sites. In Proceedings of the 29th Australian Conference on Computer-Human Interaction (pp. 77-86). ACM.

Bajnaid, A., \& Elyas, T. (2017). Exploring the Phenomena of Online Dating Platforms Versus Saudi Traditional Spouse Courtship in the 21st Century. Digest of Middle East Studies, 26(1), 74-96.

Bauman, L. J., \& Greenberg, E. (1992). The Use of Ethnographic Interviewing to Inform Questionnaire Construction. Health Education Quarterly.

Berger, L. G. (2013). Saudi Arabia. Political Insight, 4(3), 22-25.

Bhattacherjee, A. (2012). Social Science Research: Principles, USF Tampa Bay.

Bowen, W. H. (2008). The History of Saudi Arabia. Westport, Conn.: Greenwood Press. Print.

Bunton, K. (1998). Social Responsibility in Covering Community: A Narrative Case Study. Journal of Mass Media Ethics, 13(4), 232-246. https://doi.org/10.1207/s15327728jmme1304_3

Castells, M. (2001). The Internet Galaxy. New York: Oxford University Press.

Christians, C. G., \& Nordenstreng, K. (2004). Social Responsibility Worldwide. Journal of Mass Media Ethics, 19(1), 3-28.

Darawsheh, S., ALshaar, A., \& AL-Lozi, M. (2016). The Degree of Heads of Departments at the University of Dammam to Practice Transformational Leadership Style from the Point of View of the Faculty Members. Journal of Social Sciences (COES\&RJ-JSS), 5(1), 56-79.

Elyas, T., \& Picard, M. (2018). A brief history of English in Saudi Arabia. In Moskovsky, C. \& Picard, M. (Eds.), EFL in Saudi Arabia: New Insights into Teaching and Learning English. Routledge. pp.78-92. ISBN: 9781317421221.

Elyas, T., \& Picard, P. (2012). Teaching and Moral Tradition in Saudi Arabia: A Paradigm of Struggle or Pathway towards Globalization?Procedia - Social and Behavioral Sciences, 41, 1083-1086. ISSN 1877-0428. https://doi.org/10.1016/j.sbspro.2012.06.782

Fackler, M., \& Fortner, R. S. (Eds.) (2010). Ethics and Evil in the Public Sphere: Media, Universal Values \& Global Development. Cresskill, NJ: Hampton Press.

Guynn, J. (2012). Twitter's Dick Costolo on the State of Twitter, trolls and all. Los Angeles Times, 12 July 2012. Retrieved from http://www.latimes.com/business/technology/la-fi-tn-twitters-dick-costolo-onthe-state-oftwitter-trolls-and-all-20120712,0,1411049.

Hofstede, G. (1980). Culture's Consequences: International Differences in Work-Related Values. Beverly Hills: Sage.

Jawad, N. (2013). Media Censorship in Saudi Arabia. Retrieved 13 May 2013 from http://iml.jou.ufl.edu/projects/fall09/jawad_n/index.html.

Kaliski, B. S. (Ed.) (2001). Encyclopedia of Business and Finance. New York, NY: Macmillan.

Levy, N. (2009, July). Culpable Ignorance and Moral Responsibility: A Reply to FitzPatrick. Ethics, 119, 729-741. https://doi.org/10.1086/605018

Lichtenberg, J. (1990). Foundations and Limits of Freedom of Press. In Lichtenberg, J. (Ed.), Democracy and the Mass Media. Cambridge: Cambridge University Press.

Mahboob, A., \& Elyas, T. (2014). English in Saudi Arabia: A Historical and Linguistics Analysis. World Englishes, 33(1), 12-35. https://doi.org/10.1111/weng.12073.

Maqableh, M., Rajab, L., Quteshat, W., \& Khatib, T. (2015). The Impact of Social Media Networks Websites Usage on Students' Academic Performance. Communications and Network, 7(4), 159-171.

Marghalani, K., Palmgreen, P., \& Boyd, D. A. (1998). The Utilization of Direct Satellite Broadcasting (DBS) in Saudi Arabia. Journal of Broadcasting \& Electronic Media, 42(3), 297-314. https://doi.org/10.1080/08838159809364451

Masa'deh, R., Shannak, R., \& Maqableh, M. (2013). A Structural Equation Modeling Approach for Determining Antecedents and Outcomes of Students' Attitude toward Mobile Commerce Adoption. Life Science Journal, 10(4), 2321-2333.

Mills, J. L. (2009). The New Global Press and Privacy Intrusions: The Two-Edged Sword. Paper Presented at the Second Annual Berkeley-GW Privacy Law Scholars Conference, Berkeley, June 4-6. 
Novak, M. (1996). Business as a Calling: Work and the Examined Life. New York, NY: Free Press.

Obeidat, B., Tarhini, A., \& Aqqad, N. (2017). The Impact of Intellectual Capital on Innovation via the Mediating Role of Knowledge Management: A Structural Equation Modeling Approach. International Journal of Knowledge Management Studies, 8(3/4), 273-298.

Punch, K. (1998). Introduction to Social Research. London: SAGE Publications.

Rosenblatt, H. (2011). Rousseau, Constant, and the Emergence of the Modern notion of Freedom of Speech. In Powers (ed.), Freedom of Speech: The History of an Idea. Lanham: Lexington Books, pp. 133-64.

Shannak, R., Obeidat, B., \& Masa'deh, R. (2012). Culture and the Implementation Process of Strategic Decisions in Jordan. Journal of Management Research, 4(4), 257-281.

Tarhini, A., Mgbemena, C., \& Trab, M. S. A. (2015). User Adoption of Online Banking in Nigeria: A Qualitative Study. Journal of Internet Banking and Commerce, 20(3), 1-8.

\section{Copyrights}

Copyright for this article is retained by the author(s), with first publication rights granted to the journal.

This is an open-access article distributed under the terms and conditions of the Creative Commons Attribution license (http://creativecommons.org/licenses/by/4.0/). 